\title{
Avaliação da Qualidade de Vida no Trabalho em um grupo de empresas familiares localizadas em Campina Grande - PB
}

\author{
Nathália Costa Maia (Universidade Federal de Campina Grande) \\ nathaliacmaia11@gmail.com
}

\author{
Ivanildo Fernandes Araújo (Universidade Federal de Campina Grande) \\ ivanildofaraujo@gmail.com
}

Atualmente, as organizações, principalmente aquelas consideradas de grande porte, vêm dando considerável importância à formulação e implementação de estratégias, como forma de obter excelência em sua gestão e manter sua própria sobrevivência no mercado competitivo e globalizado. As empresas de pequeno porte podem buscar alternativas de transformar o ambiente de trabalho para favorecer a Qualidade de Vida no Trabalho (QVT) como fator imprescindivel para o sucesso e expansão de seus negócios, por meio de ações importantes que envolvam dimensões física, intelectual, emocional, profissional e social. Através da análise de um grupo de três empresas familiares do setor atacadista de materiais médico, cirúrgico, hospitalar e de laboratórios tomando como base a metodologia de Fernandes (1996). Dessa forma, foi possível identificar através das principais dimensões que evidenciam a QVT no grupo de empresa em estudo, $e$ através da identificação, análise e ponderação desses fatores, foram apresentadas sugestões para auxiliar as empresas do grupo em estudo.

Palavras-chave: Qualidade de Vida no Trabalho, Satisfação, Motivação. 


\section{Introdução}

Em um contexto que tem sido apresentado extremamente competitivo e oscilante, é natural que as empresas estejam cada vez mais empenhadas em praticar e promover estratégias que lhes confiram certa vantagem competitiva dentre as demais no mercado. Porém, conforme Limongi-França (2003), não adianta a organização ter independência econômica se não se importar com a qualidade de vida de seus colaboradores uma vez que o desenvolvimento da organização depende invariavelmente das pessoas que nela atuam.

Diante deste cenário, processos de mudanças relacionadas a importância do colaborador para a organização são cada vez mais aceitos em empresas que procuram consolidação e buscam a qualidade, a produtividade e a competitividade para fazer frente às concorrentes, considerando a QVT um atributo nos seus produtos ou serviços, de modo que seja obtido uma melhor interação interna na empresa, o que exige maior participação dos colaboradores nos processos organizacionais. Não se trata mais, apenas, levar os problemas de casa para o trabalho, afetando o andamento na execução das atividades, mas de levar para casa os problemas, as tensões, os receios e as angústias que são adquiridos e acumulados no ambiente de trabalho. Deste modo, novas posturas administrativas começam a surgir à medida que há a necessidade de pessoas motivadas, saudáveis e preparadas para enfrentar constantes desafios apresentados pelo trabalho.

Nesse contexto, a Qualidade de Vida no Trabalho (QVT) vem se tornando parte integrante da cultura organizacional das empresas como caminho competitivo. Segundo Dejours (1992), qualidade de vida é uma expressão de difícil conceituação, tendo em vista o seu caráter subjetivo, complexo e multidimensional. A obtenção da qualidade de vida pode ser atribuída a dependência de fatores gerais que influenciam diretamente na satisfação do trabalhador em relação ao seu trabalho, interpretada individualmente por cada colaborador, de acordo com seu modo de vida.

Segundo Fernandes (1996), “mensurar os níveis de satisfação dos empregados sobre suas condições de trabalho é também uma questão-chave para o sucesso empresarial". Diante disso, é importante dimensionar e analisar o nível de satisfação dos funcionários em relação aos vários fatores que interferem na qualidade de vida no trabalho para que a empresa consiga conhecer e saber aproveitar melhor sua força de trabalho, da mesma forma corrigir suas falhas e assim, tanto a organização como os colaboradores conquistem melhores interações e obtenham melhores resultados.

\section{Referencial Teórico}




\subsection{Qualidade nas organizações}

Com um mercado cada vez mais acirrado, as organizações deparam-se com um ambiente competitivo de alta pressão, exigindo das mesmas produtos ou serviços com padrões cada vez melhores, e muitas vezes, para manter uma posição de reconhecimento, são exigidas a serem flexíveis e inovadoras. Miranda (1994) diz que as organizações precisam gerar produtos e serviços em condições de satisfazer as demandas dos consumidores finais, sob qualquer situação. O consumidor está cada vez mais exigente e detalhista. Com as vastas opções que o mercado oferece, o seu critério de decisão mais importante é a qualidade do produto ou serviço prestado.

A maioria das pessoas concorda que qualidade é aquilo que produz satisfação, que está relacionada a um preço justo, a um produto que funciona corretamente e a um serviço prestado de forma a superar as expectativas de quem dela faz uso. (VERGUEIRO, 2002. 52p.).

Compreende-se que, de acordo com a afirmativa do autor, o propósito de que certo produto ou serviço tenha qualidade, é fundamental saber a quem ele se destina e qual a sua expectativa. Portanto, a qualidade pode ser vista na organização através de um contexto interno ou externo. Quando visto internamente, auxilia na redução de custos, aumento de produtividade e diminuição de defeitos. Quando visto externamente, facilita a confiabilidade e a fidelidade de clientes.

\subsection{Qualidade de Vida no Trabalho e sua importância}

O interesse sobre o ser humano no ambiente de trabalho foi iniciado após o trabalho desenvolvido por Frederick Taylor nos Estados Unidos no começo do Século XX, o criador da Administração Científica, segundo o pensamento de Robbins (2001), centralizou o conhecimento na medição e a estrutura do próprio trabalho e tem como objetivo criar a forma mais eficaz de realizar tarefas. Taylor criou técnicas para administração com o intuito de melhorar o desempenho da indústria, focando na segregação do trabalho e no desenvolvimento da produção individual.

Rodrigues (1994) também diz que o intuito dos princípios de Taylor era racionalizar a produção, aumentando assim a produtividade e a motivação do colaborador com a valorização do seu trabalho e proporcionando ao trabalhador condições de receber o seu salário de acordo com a sua produção. 
O trabalho faz parte da vida das pessoas desde sua existência, seja como fonte de sua própria subsistência ou de seu grupo social, seja como realização pessoal, já as mudanças fazem parte de um processo de desenvolvimento da sociedade na qual estamos inseridos. $O$ profissional satisfeito em seu local de trabalho, reflete num melhor resultado na execução do trabalho através de um bom rendimento e maior qualidade nos serviços prestados. De acordo Fernandes (1996) não se pode falar em qualidade de produtos e serviços se aqueles que vão produzi-los não têm qualidade de vida no trabalho. Dessa forma, não adianta a organização querer oferecer o melhor produto ou serviço sabendo que não oferece condições favoráveis de trabalho aos seus colaboradores.

A Qualidade de Vida no Trabalho é um conjunto complexo no qual envolve uma constelação de fatores, sendo estes: Satisfação com o trabalho que está sendo executado, possibilidades de futuro na organização, reconhecimento por resultados alcançados, melhoria no salário, melhores benefícios adquiridos como relacionamento humano dentro da equipe e da organização, no ambiente psicológico e físico de trabalho, maior liberdade de atuar e responsabilidade de tomar decisões e consequente maior possibilidade de estar engajado e de participação ativamente na organização (CHIAVENATO, 2010).

Diante disso, observa-se que é difícil definir um padrão de qualidade de vida que seja adequado para todos, pois cada ser humano têm peculiaridades e necessidades distintas. Por isso, é imprescindível que a empresa esteja preocupada com as questões relacionadas à qualidade de vida, com o intuito de melhor gerenciar as necessidades dos colaboradores e, assim, tornar o ambiente empresarial mais produtivo.

\subsection{Satisfação no trabalho}

Como diz Pietersen (2005), promover a satisfação no trabalho é valioso para as empresas visto que o trabalhador satisfeito tende a auxiliar, através do seu trabalho, a organização oferecer produtos e serviços para seus clientes com qualidade diferenciada, o que aumenta os níveis de absorção dos produtos e a divulgação dos serviços de boa qualidade.

Mudanças no nível de satisfação de um indivíduo em relação a outro é comum, pois cada pessoa tem suas necessidades individuais próprias, mesmo exercendo atividades idênticas ao longo de uma jornada de trabalho. Diante disso, é de extrema importância que os gestores estejam atentos às mudanças no comportamento dos indivíduos e equipes de trabalho através de percepções no que se refere ao entendimento da motivação dos colaboradores. Bergamini 
(2008) mostra que o modelo de Maslow propõe a noção de necessidade como fonte de energia das motivações existentes no interior das pessoas. A teoria da hierarquia de necessidades, de acordo com Matsuoka e Silva (2013) foi proposta pelo psicólogo norte americano Abraham Maslow, com o intuito de demonstrar a relação existente entre o comportamento motivacional e as diferentes necessidades humanas. A teoria propõe que os fatores de satisfação do ser humano dividem-se em cinco níveis organizados em forma de pirâmide, sendo a base da pirâmide compreendida como as necessidades de nível básico e fundamental, como as necessidades fisiológicas e de segurança; o topo da pirâmide é formado pelas necessidades de nível elevado, ou de reconhecimento, sendo as necessidades sociais, de estima e de autorrealização. À medida que um nível de necessidade é atendido, o próximo torna-se dominante. Robbins (2002) define cada um dos níveis de necessidade conforme observado na Figura 1:

Figura 1 - Teoria das necessidades de Maslow

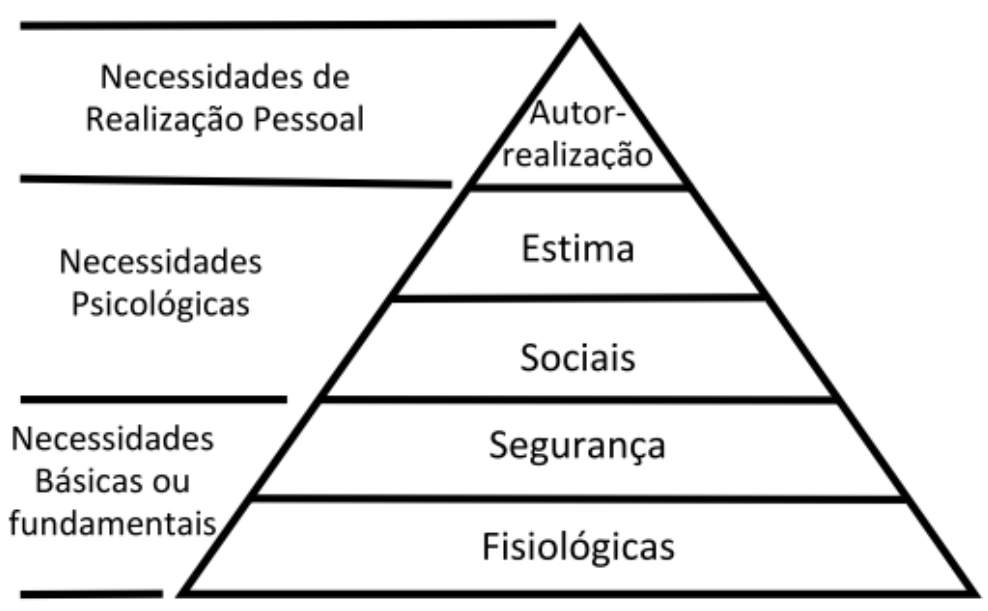

Fonte: Adaptado de Robbins (2002)

De acordo com a teoria, um indivíduo só irá ser motivado por um nível mais superior de necessidades quando os níveis anteriores já estiverem satisfatoriamente preenchidos para ele. A transparência nas relações entre empresa e o entendimento dos fatores intrínsecos de motivação na percepção dos colaboradores podem impulsionar a satisfação no trabalho, pois, como diz Paula (et al., 2011), a insegurança, ou dúvida, com as políticas organizacionais, produz incerteza no indivíduo em relação às tratativas que a organização poderá adotar, podendo ser um gerador de insatisfação no trabalho. Sendo, portanto, necessário e simples diagnosticar e gerenciar pontos positivos e negativos dessa relação para impactar positivamente entre os colaboradores. 


\section{Metodologia}

\subsection{Caracterização das empresas em estudo}

As três empresas familiares estudadas são classificadas segundo o SEBRAE (2018), segundo o faturamento anual e número de empregados, como de Pequeno Porte (EPP), atuando sob Classificação Nacional de Atividades Econômicas - CNAE, 4645-1, no comércio atacadista de instrumentos e materiais para uso médico, cirúrgico, hospitalar e de laboratórios, no mercado desde 1998, tendo como seus maiores clientes órgão públicos. Os donos são formados pelo pai, com a empresa denominada A e seus filhos, com as empresas B e C.

\subsection{Classificação da pesquisa}

A pesquisa classifica-se, segundo o método, como descritiva qualitativa, conforme Rodrigues (1994), o método descritivo qualitativo consiste de uma "observação por meio de perguntas diretas ou indiretas, de problemas de unidades relativamente numerosas, colocadas em situações naturais, destinada a obter respostas para serem submetidas à análise quantitativa”. Procurou-se analisar a Qualidade de Vida no Trabalho segundo a percepção dos colaboradores em um grupo de empresas familiares do ramo médico hospitalar localizadas na cidade de Campina Grande - PB.

\subsection{População e amostra}

A população desta pesquisa constitui-se dos trabalhadores das empresas analisadas neste estudo de caso, que totalizam trinta (30) funcionários efetivos, sendo quatorze (14) da A, doze (12) da B e quatro (04) da empresa C. Devido ao pequeno número de funcionários, uma vez que trata-se de pequenas empresas, os sujeitos pesquisados foram todos, de cada uma das três empresas, ou seja, a totalidade da população.

\subsection{Etapas da pesquisa}

Esta pesquisa foi desenvolvida, inicialmente, pela revisão da literatura e posterior preparação do instrumento de coleta de dados, por meio de um questionário estruturado, baseando-se no trabalho de Fernandes (1996) para avaliar dez fatores relacionados à QVT. O questionário, com perguntas abertas e fechadas e, dividido em 10 (dez) blocos, estruturados conforme detalha o Quadro 1, contendo variáveis das quais o entrevistado deve avaliar seu nível de satisfação dentro da escala proposta. 
Quadro 1 - Blocos relacionados à QVT no questionário adaptado de Fernandes (1996)

\begin{tabular}{|c|c|c|}
\hline $\begin{array}{c}\text { Bloco } 1 \\
\text { QVT GLOBAL } \\
\text { DAS EMPRESAS }\end{array}$ & & $\begin{array}{l}\text { Posicionamento do Funcionário em } \\
\text { relação à QVT em seu trabalho de forma } \\
\text { geral }\end{array}$ \\
\hline $\begin{array}{l}\text { Bloco } 2 \\
\begin{array}{l}\text { CONDIÇÕES DE } \\
\text { TRABALHO }\end{array}\end{array}$ & & $\begin{array}{l}\text { Explora-se a satisfação do funcionário de } \\
\text { acordo com as condições físicas que } \\
\text { executam seu trabalho, analisando } \\
\text { variáveis como limpeza, arrumação e } \\
\text { nocividade do ambiente }\end{array}$ \\
\hline $\begin{array}{l}\text { Bloco } 3 \\
\text { SAÚDE }\end{array}$ & & $\begin{array}{l}\text { Analisa-se a satisfação dos empregados } \\
\text { em relação às ações da empresa o que se } \\
\text { refere à saúde. }\end{array}$ \\
\hline $\begin{array}{l}\text { Bloco } 4 \\
\text { SAÚDE }\end{array}$ & & $\begin{array}{l}\text { Analisa-se o nível de satisfação quanto a } \\
\text { identidade com a função exercida, } \\
\text { ralações interpessoais, reconhecimento } \\
\text { do trabalho e orientação para pessoas }\end{array}$ \\
\hline Bloco 5 & & $\begin{array}{l}\text { Analisa-se a satisfação do funcionário } \\
\text { quanto a política de remuneração da } \\
\text { empresa, em relação aos salários fixos e } \\
\text { variáveis (comissões, participação nos } \\
\text { lucros) }\end{array}$ \\
\hline BIoco 6 & & $\begin{array}{l}\text { Procura-se constatar a percepção do } \\
\text { funcionário em termos de aceitação e } \\
\text { engajamento em ações para ele } \\
\text { solicitadas, no sentido de gerar sua } \\
\text { participação afetiva através da } \\
\text { criatividade e expressão pessoal. }\end{array}$ \\
\hline Bloco 7 & & $\begin{array}{l}\text { Analisa-se a opinião dos colaboradores } \\
\text { quanto a eficiência no fluxo de } \\
\text { informações repassadas e o conhecimento } \\
\text { de metas na empresa em que trabalha. }\end{array}$ \\
\hline $\begin{array}{l}\text { Bloco } 8 \\
\text { IMAGEM DA } \\
\text { EMPRESA }\end{array}$ & & $\begin{array}{l}\text { Analisa-se a percepção dos funcionários } \\
\text { quanto a imagem interna e externa. }\end{array}$ \\
\hline $\begin{array}{c}\text { Bloco } 9 \\
\begin{array}{c}\text { RELAÇÃO CHEFIA- } \\
\text { SUBORDINADO }\end{array}\end{array}$ & & $\begin{array}{l}\text { Analisa-se a satisfação do funcionário de } \\
\text { acordo com a igualdade o tratamento e } \\
\text { orientação técnica para execução e } \\
\text { atividades. }\end{array}$ \\
\hline $\begin{array}{c}\text { Bloco } 10 \\
\text { ORGANIZAÇÃO } \\
\text { DO TRABALHO }\end{array}$ & & $\begin{array}{l}\text { Analisa-se as formas de trabalho e sua } \\
\text { organização, relacionando com inovação } \\
\text { dos métodos e processos, como também } \\
\text { rítmo de trabalho. }\end{array}$ \\
\hline
\end{tabular}

Fonte: Adaptado de Fernandes (1996) 
Os blocos 1 avalia a percepção dos entrevistados quanto o nível global de QVT e as condições de trabalho da empresa, sendo uma pergunta aberta, sem a necessidade de utilização de escala gráfica. Além dos blocos, foram solicitados ao funcionário alguns dados de identificação, como Setor ou Departamento, função, idade, gênero, nível de instrução e tempo de empresa e um espaço para observações, no qual o funcionário teve a liberdade de registrar depoimentos marcantes de sua percepção, que auxiliam no andamento da pesquisa.

Utilizou-se uma escala gráfica para a apuração dos resultados, conforme a Figura 2, atribuindo-se valores de 1 a 5 para as respostas, onde 1 é insatisfação total, 3 permanece neutro e 5, satisfação total. Para a interpretação dos resultados, foi estabelecido o limite de 3 (indiferente) para as variáveis, assim sendo, as variáveis que obtiveram índices inferiores a 3 , são consideradas deficientes.

Figura 2 - Escala gráfica para o Nível de Satisfação

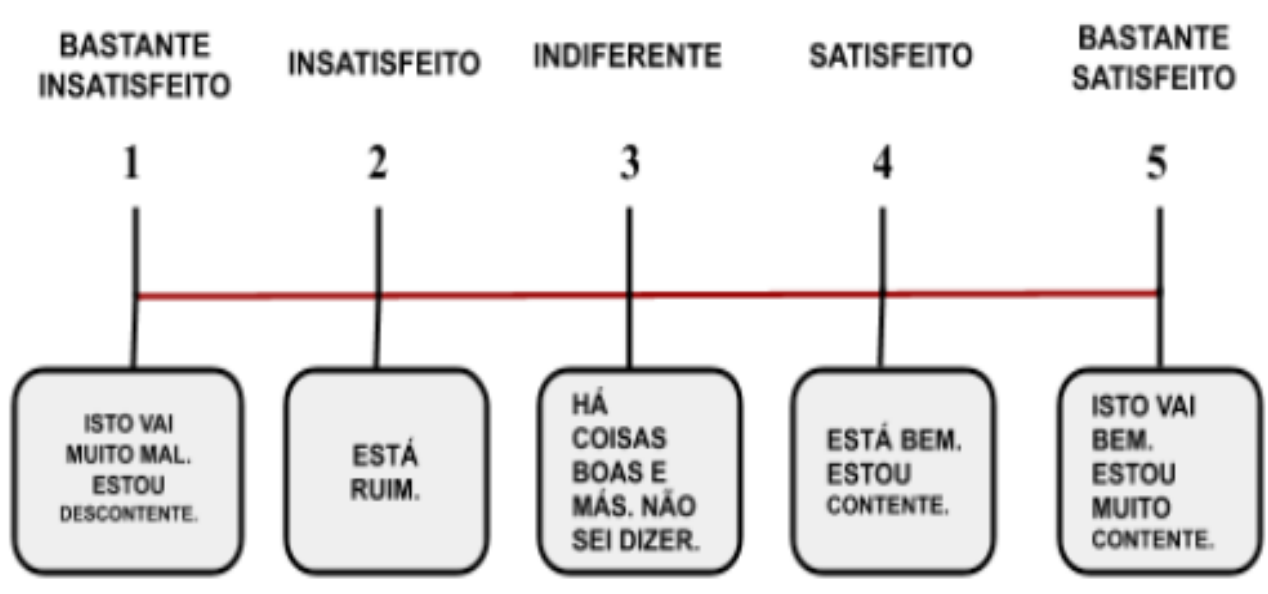

Fonte: Adaptado de Fernandes (1996)

Assegurou-se o anonimato dos entrevistados, visto que não é necessário sua identificação. Posteriormente, os depoimentos coletados através dos questionários foram tratados estatisticamente, quantificando-os de acordo com a escala de satisfação proposta na Figura 2. Por fim, a partir da análise e interpretação dos resultados, foram identificados os aspectos com menor desempenho, dentre os diversos indicadores de QVT, para a partir destes direcionar ações de melhoria a serem adotadas, pretendendo-se auxiliar as empresas na aplicação de melhorias adequadas à mobilização e satisfação do pessoal.

\section{Análise e discussão dos resultados}




\subsection{Análise global dos fatores da QVT}

Para um melhor direcionamento das ações, os resultados obtidos pelos fatores são apresentados de uma forma global no Quadro 2 abaixo.

Quadro 2 - Média geral dos Blocos da QVT

\begin{tabular}{|l|r|}
\hline \multicolumn{1}{|c|}{ BLOCO } & \multicolumn{1}{|c|}{ MÉDIA } \\
\hline 2 - CONDIÇÕES DE TRABALHO & 4,05 \\
\hline 3 - SAÚDE & 3,6 \\
\hline 4 - MORAL & 4,02 \\
\hline 5 - COMPENSAÇÃO & 3,47 \\
\hline 6 - PARTICIPAÇÃO & 4,12 \\
\hline 7 - COMUNICAÇÃO & 4,0 \\
\hline 8 - IMAGEM DA EMPRESA & 4,09 \\
\hline 9 - RELAÇÃO CHEFIA-SUBORDINADO & 4,02 \\
\hline 10 - ORGANIZAÇÃO DO TRABALHO & 3,53 \\
\hline MÉDIA GERAL & $\mathbf{3 , 8 8}$ \\
\hline
\end{tabular}

Fonte: Dados da pesquisa

Os itens relativos à Organização no trabalho $(3,53)$, Compensação (média: 3,47) e Saúde $(3,6)$ são os que apresentaram menor índice de satisfação na opinião dos funcionários, merecendo cuidados mais efetivos por parte da gestão. O Quadro 2 ilustra a proporção de escolhas entre a escala estabelecida nesses itens.

Quadro 3 - Média das variáveis do Bloco 5

\begin{tabular}{|l|r|}
\hline \multicolumn{2}{|c|}{ BLOCO 5 - COMPENSAÇÃO } \\
\hline VARIÁVEL & \multicolumn{1}{|c|}{ MÉDIA DO NÍVEL DE SATISFAÇÃO } \\
\hline SALÁRIO FIXO & 3,59 \\
\hline SALÁRIO VARIÁVEL & 3,34 \\
\hline MÉDIA GERAL DO BLOCO & $\mathbf{3 , 4 6}$ \\
\hline
\end{tabular}

Fonte: Dados da pesquisa

Relaciona-se o nível de satisfação no bloco Compensação, como observado no Quadro 3, por serem estas empresas de pequena porte, e não dispõem de recursos suficientes para oferecerem a seus funcionários salários e vantagens financeiras mais atrativos, acima do mercado. Assim, essa dimensão da QVT não é vista como uma vantagem competitiva para a empresa, já que na percepção dos trabalhadores a satisfação quanto à compensação salarial, não 
é um diferencial motivador, sendo necessário que a empresa avalie a viabilidade de melhorar a compensação variável para melhor percepção e consequente melhoria desse indicador.

Em relação à média obtida de 3,53 pontos no Bloco 10, que avalia a Organização do Trabalho, descrito no Quadro 4, é justificado frente às observações nos relatos dos funcionários, por ser o método de trabalho monótono e não oferecer diversificação, então avaliaram esse indicador entre indiferentes e satisfeitos. O nível 3 (indiferente) também é escolhido pelos funcionários com frequência, e, em algumas observações na visão dos funcionários, é citado que o método de trabalho e como as tarefas estão sendo executadas, não é bom. Sendo, portanto, necessário que esse grupo de empresas invista para melhoria, otimização, treinamento e padronização dos processos internos, o que vai melhorar a percepção de QVT.

Quadro 4 - Média das variáveis do Bloco 10

\begin{tabular}{|l|r|}
\hline \multicolumn{2}{|c|}{ BLOCO 10 - ORGANIZAC̃̃O DO TRABALHO } \\
\hline VARIÁVEL & $\begin{array}{c}\text { MÉDIA DO NÍVEL DE } \\
\text { SATISFAÇÃO }\end{array}$ \\
\hline $\begin{array}{l}\text { INOVAÇÃO DE MÉTODOS E } \\
\text { PROCESSOS }\end{array}$ & 3,69 \\
\hline VARIEDADE NA EXECUÇÃO DE & 3,69 \\
TAREFAS & 3,21 \\
\hline RITMO DE TRABALHO & $\mathbf{3 , 5 3}$ \\
\hline MÉDIA DO BLOCO & \\
\hline
\end{tabular}

Fonte: Dados da pesquisa

Os funcionários também não estão suficientemente satisfeitos quanto a assistência à Saúde dos funcionários e seus famílias, cuja avaliação obteve média 3,6, como observa-se no Quadro 5. É possível que essa pontuação média não tenha sido melhor, frente ao que ocorre, conforme relatado, devido ao acúmulo de trabalho, quando o trabalhador está indisposto ao adoentado e necessitam de repouso, não conseguem parar. Esse fato não ocorre por exigência da empresa de forma direta, mas o colaboradores se acham no compromisso e que é necessário continuar trabalhando, em alguns casos, mesmo debilitados para evitar atrasos nas entregas e mais problemas futuros. Para melhorar esse indicador de QVT a empresa poderia adotar alguns benefícios aos funcionários e seus familiares, como criar um banco de receita médica, onde o trabalhador pudesse adquirir medicamentos e pagar a preço diferenciado frente aos custo e com desconto em carteira. 
Quadro 5 - Média das variáveis do Bloco 3

\begin{tabular}{|l|r|}
\hline \multicolumn{2}{|c|}{ BLOCO 3 - SAÚDE } \\
\hline VARIÁVEL & MÉDIA DO NÍVEL DE SATISFAÇÃO \\
\hline ASSISTÊNCIA AO FUNCIONÁRIO & 3,72 \\
\hline ASSISTÊNCIA À FAMÍLIA DO & 3,48 \\
FUNCIONÁRIO & 3,6 \\
\hline MÉDIA GERAL DO BLOCO & \\
\hline
\end{tabular}

Fonte: Dados da pesquisa

As variáveis, como ritmo de trabalho $(3,21)$, assistência à família do funcionário $(3,34)$ pertencente do bloco saúde, salário fixo $(3,48)$ e salário variável $(3,59)$, apesar de superiores ao nível 3, ambas do bloco compensação, indicam que os funcionários ainda não estão satisfeitos, mas já estão a percepção um pouco além de indiferentes a estes indicadores de QVT. Embora superiores ao nível 3 (indiferente), percebe-se uma leve tendência as valores já próximos a 4 (satisfeito) o que indica uma boa oportunidade do grupo estudado buscar investir em resoluções aos problemas citados e usar estratégias que alavanquem um melhor desempenho da instituição em relação a QVT, melhorando a percepção da satisfação desses quesitos, por parte do colaborador, o que implicará melhorias em outros indicadores de desempenho do grupo empresarial. Os demais Blocos de indicadores da QVT, sendo eles Condições de Trabalho $(4,05)$, Moral (4,02), Participação (4,12), Comunicação $(4,0)$, Imagem da Empresa $(4,09)$ e Relação Chefia-Subordinado (4,02), todos com médias superiores a 4 (satisfeitos), mesmo sendo considerados pelos colaboradores pontos positivos influenciadores na Qualidade de Vida no Trabalho, merecem atenção da gestão para que o bom reconhecimento como observado nos questionários seja mantido e usado como fator estratégico para alavancar o desempenho do grupo de empresas.

Em relação à dimensão Condições do Trabalho, a busca por tentar promover um ambiente propício e saudável é necessário e determinante para a satisfação do colaborador, identificando pontos nos quais os funcionários ainda não possuam a devida clareza em relação às suas atividades. Como observado no Bloco Moral, a fim de descomplicar a sua rotina de trabalho e também procurar entender, individualmente, cada colaborador, quais são os conflitos internos que estão impactando na insatisfação no trabalho e, assim, oferecer mecanismos de auxílio que promovam a solução do problema. 
Nas variáveis do Bloco Participação, apesar da avaliação indicar alta satisfação, necessitam não somente de boa liderança, para integrar cada vez mais funcionário com a filosofia da empresa, como também manter a participação ativa dos colaboradores, uma vez que, quanto mais engajado o colaborador sentir-se com a empresa na qual trabalha, mais propenso ele estará para denominar-se como parte importante da organização, influenciando diretamente no seu rendimento. No Bloco Comunicação observou-se que os funcionários consideram que as informações passadas pela administração para desenvolver atividades de trabalho é uma qualidade que contribui para a satisfação no trabalho e precisa melhorar. É importante que, para uma empresa obter resultados consideráveis, é preciso mudar o cenário do que se considera um chefe e um líder.

No bloco Relação Chefia-Subordinado, a variável que trata da igualdade no tratamento, analisada separadamente, obteve nível de satisfação menos significativo, pois, como também foi relatado nas observações, algumas situações pontuais descritas pelos entrevistados os fizeram dar uma nota menor. A empresa precisa se conscientizar que a relação chefesubordinado deve ser visto, hoje, como uma convivência líder-colaborador. Como também, conscientizar-se de que uma comunicação transparente é ferramenta essencial para essa relação, pois, para muitos dos entrevistados, a maior dificuldade é superar a barreira que, por vezes, existe com o empregador, ou seja com o dono da empresa.

A partir da pesquisa, constatou-se que o nível de satisfação geral em relação à Qualidade de Vida no Trabalho, no grupo de empresas em questão, apresenta-se significativamente tendendo a satisfatório $(3,88)$, o que demonstra que a pesquisa contribui, com alguns pontos a serem ajustados, para melhorar o nível de motivação e satisfação de seus funcionários. Dessa forma, é necessário mudanças que consigam alavancar a avaliação da QVT global no nível encontrado, que apesar de estar em um patamar aceitável, a gestão da empresa pode adotar medidas que acarretem em mudanças positivas, favorecendo todos os envolvidos e o desempenho geral da empresa.

\subsection{Propostas de melhorias por blocos de QVT}

No conjunto dos dados coletados, percebe-se que dentre as variáveis de cada blocos, nenhuma obteve média inferior ao nível 3 (indiferente), constatando que a empresa, mesmo sendo de pequeno porte, fornece segurança e satisfação em diversos pontos analisados neste trabalho. Isto significa que há efetividade das ações gerenciais referentes a aspectos psicossociais que se refletem na motivação e moral dos profissionais, porém, é necessário uma 
certa atenção individual para pontos importantes, no sentido de reunir esforços para adoção de ações, objetivando ainda mais a melhoria da satisfação do funcionários.

Através dessas evidências identificadas nos dados obtidos no questionário e nas observações de cada um dos blocos, pode-se, por parte da gerência, definir melhor a divisão das tarefas, através de um gerenciamento de rotina, propondo atividades diárias, semanais, quinzenais e mensais, de forma organizada, a fim de evitar o acúmulo de atividades. Uma opção é o oferecimento de palestras para os colaboradores com temas sobre planejamento financeiro e, também, a criação de um plano para uma melhor participação nos lucros.

Esses direcionamentos poderiam mudar a percepção do colaborador sobre a compensação de forma satisfatória, influenciando também em uma melhor Qualidade de Vida no Trabalho. Facilitar e propor otimizações que aplicam em melhorias no layout das empresas, por exemplo, principalmente no setor de processamento dos pedidos, facilitando o fluxo das mercadoria e melhoria nos processos.

Uma outra ação seria a otimização no sistema de software, diminuindo o tempo de digitação dos pedidos com implantação de códigos de barra no setor de vendas e no almoxarifado. Assim como, melhorar o planejamento logístico para otimizar as entregas, e consequente melhoria dos processos internos, facilitando a clareza e entendimento das atividades a serem executadas, reduzindo e distribuindo melhor as atividades entre os colaboradores, impactando a carga de trabalho para os níveis adequados facilitando que o colaborador não sinta-se sobrecarregado nas épocas que necessitam grande demanda de trabalho. Para isso, é imprescindível aplicar novos métodos de trabalho e o planejamento das atividades o que influenciarão diretamente na QVT dos colaboradores.

\section{Considerações finais}

A pesquisa realizada demonstra que os funcionários, das empresas em estudo, são satisfeitos em alguns aspectos, no entanto, há pontos identificados que as empresas precisam investir sua atenção para melhor a Qualidade de Vida no Trabalho e consequente, satisfação dos colaboradores. A pesquisa aponta que a empresa tem disposição em investir na melhoria do ambiente de trabalho de maneira a aumentar do nível de satisfação e melhorar a produtividade dos funcionários.

Embora um programa de QVT exija certos investimentos, sempre existe algo que se possa fazer e que esteja ao alcance de qualquer organização, com pouco ou nenhum investimento financeiro, independentemente do seu porte, para que o trabalhador perceba 
mudanças e melhorias, seja nos processos internos, seja uma atitude de respeito e humanidade, o que refletirá não somente em sua qualidade de vida no trabalho e no desempenho melhor de sua função, como também na produtividade da organização.

Conclui-se, portanto, que a Qualidade de Vida no Trabalho não está relacionada apenas às melhorias nas condições físicas e de instalações, atendimento a melhorias salariais, redução da carga de trabalho e outras medidas do gênero que estão diretamente associados a custos para as empresas. É importante considerar, também, outros elementos que podem ser trabalhados e que não significam expressamente desembolso financeiro e, contribuem para a melhoria das relações entre o indivíduo, sua rotina de trabalho e a própria empresa onde atua. $\mathrm{Na}$ verdade, são as reformulações do trabalho em si que constituem o objetivo principal das ações implicadas na Qualidade de Vida no Trabalho, visando garantir maior eficácia e produtividade e, ao mesmo tempo, o atendimento das necessidades básicas dos trabalhadores.

É importante ressaltar que a pesquisa sobre QVT deva ser realizada periodicamente, monitorando os resultados obtidos, detectando outros aspectos que necessitam de solução. Conclui-se, ainda, que a qualidade de vida no trabalho busca humanizar as condições de trabalho a que as pessoas estão expostas no seu dia-a-dia, no sentido de alinhar os objetivos dos trabalhadores e da organização. Priorizar o viver com qualidade e ter consciência da rapidez com que a vida passa, são atitudes que nos estimulam a buscar, a cada dia, mecanismos para a melhor convivência no trabalho.

\section{REFERÊNCIAS}

BERGAMINI, C. W. Motivação nas organizações. 5.ed. São Paulo: Atlas, 2008

CHIAVENATO, I. Gestão de pessoas - 2. Ed. Rio de Janeiro: Campus, 2004.

DEJOURS, C. A loucura do trabalho: estudo da psicopatologia do trabalho. São Paulo: Cortez/Oboré, 1992.

FERNANDES, E. C. Qualidade de Vida no Trabalho: como medir para melhorar. 2 ed. Salvador: Casa da Qualidade, 1996.

LIMONGI- FRANÇA, A.C. Qualidade de vida no trabalho: conceito e prática na sociedade pós-industrial. São Paulo, Atlas 2004.

MATSUOKA, L. T.; SILVA, J. J. Os eventos e a hierarquia das necessidades humanas de Maslow: conjecturas na sociedade contemporânea. Colloquium Humanarum, Presidente Prudente, v. 10, p. 633-639, 2013.

MIRANDA, R. L. Qualidade total: rompendo as barreiras entre a teoria e a prática. 2 ed. São Paulo: Makron Books, 1994.

PAULA, P. D., et al. Clima e cultura organizacional em uma organização pública. Gestão e Regionalidade, São Caetano do Sul, v. 27, n. 81, p. 59-73, set 2011. 
PIETERSEN, C. Job satisfaction of hospital nursing staff. Journal of Human Resource Management, v. 3, n. 2, p. 19-25, 2005.

ROBBINS, Stephen P. Administração: Mudanças e Perspectivas. São Paulo. Editora: Saraiva, 2001

RODRIGUES, M. V. C. Qualidade de vida no trabalho: evolução e análise no nível gerencial. 7. ed. Rio de Janeiro: Vozes, 1994.

VERGUEIRO, Waldomiro. Qualidade em serviços de informação. São Paulo: Arte e Ciência, 2002. 